\title{
Transporte público em favelas: análise da percepção da acessibilidade ao teleférico do alemão
}

\author{
Carolinne de Morais Gonçalves ${ }^{1}$, Renata Albergaria de Mello Bandeira ${ }^{2}$ \\ ${ }^{1}$ Instituto Militar de Engenharia, Rio de Janeiro, RJ, Brasil, carolinneuff@gmail.com \\ 2Instituto Militar de Engenharia, Rio de Janeiro, RJ, Brasil, re.albergaria@gmail.com
}

\section{Recebido:}

14 de novembro de 2016

Aceito para publicação:

21 de maio de 2017

Publicado:

31 de agosto de 2017

Editor de área:

Helena Beatriz Cybis, UFRGS

\section{Palavras-chaves:}

Favela.

Acessibilidade.

Transporte público.

Teleférico.

\section{Keywords:}

Shanty town.

Accessibility.

Public transportation.

Cable car.

DOI:10.14295/transportes.v25i2.1280

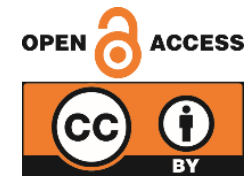

\begin{abstract}
RESUMO
Entre 2008 e 2014, foram desenvolvidas, no Rio de Janeiro, algumas iniciativas na tentativa de reduzir os problemas de transporte urbanos em comunidades carentes, como a instalação do teleférico no Complexo do Alemão. Porém, o número de passageiros deste serviço é muito baixo em relação à sua capacidade. Neste contexto, este trabalho apresenta uma análise da acessibilidade às estações do teleférico, com base em uma pesquisa realizada com 100 residentes do Complexo usuários do sistema. A análise estatística (teste $t$, análise de variância e de clusters) foi realizada para comparar as percepções dos passageiros de diferentes estações com o objetivo de identificar se as características do entorno influenciam a decisão de usar o teleférico. Os resultados indicam que, segundo as percepções dos passageiros, a baixa acessibilidade física, a falta de infraestrutura local e a não integração com os serviços de transporte complementar existentes colaboram com o atual padrão de demanda.
\end{abstract}

\section{ABSTRACT}

Some initiatives were developed, between 2008 and 2014, in an attempt to reduce urban transport problems in poor communities in the city of Rio de Janeiro, such as the implementation of the cable car system in Complexo do Alemão. Nonetheless, the demand for this service is very low in relation to its capacity. In this context, this paper aims to present an analysis of the accessibility to the cable car stations, based on a survey of 100 residents who as passengers of this transport system. Statistical analysis (such as t-test, analysis of variance and clusters analysis) were conducted in order to compare the perceptions of passengers from different stations with the purpose of identifying wheather the characteristics of the surrounding influence or not the decision to use the cable car system and thus the demand for the service. The results indicate that, according to passengers' perceptions, poor physical accessibility, lack of local infrastructure, and non-integration with the existing complementary transport services contribute to the current pattern of demand.

\section{INTRODUÇÃO}

Alternativas de transportes urbanos, voltadas para diminuir a pobreza e a desigualdade, ainda não são amplamente discutidas no Brasil, embora as precárias condições de mobilidade se coloquem como obstáculos à superação da pobreza e da exclusão social dos cidadãos mais carentes do país (ITRANS, 2004; Lindau et al., 2011). Além disto, a topografia acidentada (morros e encostas) é uma situação comum às favelas brasileiras, em especial as cariocas, cujos estreitos e íngremes canais viários restringem a instalação de modalidades convencionais de transporte coletivo nestas comunidades.

No Rio de Janeiro, foram desenvolvidas, entre 2008 e 2014, algumas iniciativas na tentativa de diminuir os grandes problemas de transporte urbanos em comunidades carentes, gerados por décadas de crescimento descontrolado, falta de planejamento e de fiscalização. Entre estas iniciativas, destaca-se a implantação de sistemas de transporte com tecnologias baseadas em propulsão a cabo (em inglês, CablePropelled Transit - CPT), como os planos inclinados dos morros Dona Marta e do Pavão-Pavãozinho, o 
sistema de elevadores do Morro do Cantagalo e os teleféricos do Morro da Providência e do Complexo do Alemão, sendo este último o objeto de estudo deste artigo.

o Complexo do Alemão é um conjunto formado por 12 comunidades, na zona norte do Rio de Janeiro. 0 crescimento urbano não planejado nesta área com alta declividade acarretou na dificuldade de acesso e consequente redução da mobilidade. Assim, os deslocamentos internos no Complexo são, em sua maioria, realizados a pé ou por transporte informal, praticado por Kombis (cabritinhos) e mototáxis (Meirelles et al., 2012). Em 2011, o sistema de teleférico no Complexo do Alemão foi implantado com intuito de facilitar a mobilidade dos moradores da comunidade, que possuíam o direito de viajar gratuitamente após o cadastro na estação Bonsucesso. Para os visitantes, havia dois tipos de tarifa: $\mathrm{R} \$ 5,00$ para pagamentos em dinheiro e R\$1,00 para pagamentos com os cartões RioCard VT, Expresso, Bilhete Único e Bilhete Único Carioca.

O teleférico do Complexo do Alemão, que teve como inspiração o modelo adotado em Medellín, na Colômbia, é composto por seis estações - Bonsucesso, Adeus, Baiana, Alemão, Itararé e Palmeiras, dispostas em 3,4km de extensão. A viagem completa (da estação Bonsucesso a Palmeiras) dura cerca de 20 minutos, enquanto para se completar o mesmo trajeto a pé se levaria aproximadamente uma hora (Silva, 2012). Entretanto, apesar do Teleférico do Alemão estar integrado aos trens da SuperVia, não houve um planejamento urbano e de transportes compatíveis. 0 sistema nunca atingiu a meta esperada com relação à estimativa da demanda. Em 2014, o teleférico chegou a transportar 12 mil passageiros por dia, embora estivesse projetado para atender até 30 mil. Por problemas de segurança no Complexo, esta demanda se reduziu ainda mais em 2015 (em média, 9.000 passageiros por dia) (Gonçalves, 2015).

Para a implantação do teleférico do Complexo do Alemão, que foi concebido como um ícone do projeto das Unidades de Polícia Pacificadora (UPP) do governo estadual e das obras do Programa de Aceleração do Crescimento (PAC) do governo federal nas favelas cariocas, foram investidos US\$ 103 milhões (Silva, 2012). Contudo, devido à crise econômica do governo do estado do Rio de Janeiro e a problemas relacionados ao processo licitatório para a sua administração, o sistema chegou a ser paralisado por diversas vezes, até que, em setembro de 2016, o serviço foi suspenso por tempo indeterminado devido ao desgaste de um dos cabos de tração e à falta de repasses do governo estadual ao consórcio que o administra.

Os problemas enfrentados pelo sistema do teleférico do Alemão são de cunho político, administrativo e social. Porém, devido ao alto investimento já realizado e aos benefícios que este sistema pode trazer devido ao seu potencial social e de mobilidade para a região, é importante o desenvolvimento de iniciativas por parte do poder público para resolver estas questões. Contudo, mesmo que os problemas administrativos, políticos e de segurança na comunidade sejam sanados, a questão da demanda continua sendo um empecilho para a afirmação deste sistema de transporte. Aspectos como a baixa acessibilidade física e a falta de integração com o transporte vigente no interior do complexo (transportes informais) devem ser considerados para uma melhor explicação da baixa adesão ao sistema.

Neste contexto, o trabalho tem como objetivo apresentar uma análise da acessibilidade às estações de Teleférico do Alemão, com base na percepção dos passageiros. Convém destacar que o conceito de acessibilidade é definido como uma medida de esforço para se transpor uma separação espacial com o objetivo de exercer atividades cotidianas (Raia Junior et al., 1997), tendo o transporte como parte integrante para tornar possível o acesso das pessoas aos locais de estudo, emprego, lazer e equipamentos públicos (Lima, 1998). Portanto, foi realizada uma análise estatística com o objetivo de comparar as percepções dos usuários de cada estação e determinar se as características do entorno influenciam ou não a decisão de usar o teleférico e, consequentemente, a demanda pelo serviço.

$\mathrm{O}$ artigo é apresentado conforme a seguinte estrutura: inicialmente, descreve-se a tecnologia CPT como alternativa de transporte público a ser implantada nas favelas. A seção 3 apresenta os métodos para avaliar o espaço do pedestre e a seção 4 aborda metodologia de pesquisa utilizada. A seção 5 analisa os resultados da pesquisa de campo referente ao sistema do teleférico do Complexo do Alemão. Enfim, 
as principais conclusões e sugestões para novas pesquisas são apresentadas na seção 6.

\section{TECNOLOGIA CPT: ALTERNATIVA PARA O TRANSPORTE PÚBLICO EM FAVELAS}

A topografia irregular de algumas cidades e a configuração informal do espaço comum dificultam ou impedem a implantação dos meios de transporte convencionais em favelas. Assim, tecnologias alternativas de transporte público, baseadas em propulsão a cabo, começaram a ser implantadas em áreas de baixa renda com restrições geográficas e, quando integradas ao transporte público de alta capacidade (metrô e trens), auxiliam na melhoria da mobilidade da população residente em favelas. Algumas cidades da América Latina, como Medellín, Caracas e Rio de Janeiro, adotaram tecnologias baseadas no sistema de propulsão a cabo, denominadas Cable-Propeled Transit (CPT), que abrangem o Aerial Ropeway Transit (ART) e o Funicular (ou plano inclinado) (Lindau et al., 2011; Creative Urban Project, 2013). Neste artigo, apresenta-se apenas a tecnologia ART, pois é a subdivisão do sistema CPT em que está incluso o teleférico.

A tecnologia ART é composta por sistemas de transporte aéreo em que os passageiros são transportados por uma cabine suspensa puxada por cabos (Alshalalfah et al., 2010). Entre as tecnologias ART utilizadas no meio urbano, destacam-se o Monocable Detachable Gondola (MDG), o Bicable Detachable Gondola (BDG), o Tricable Detachable Gondola (TDG/3S) e o Aerial Tram, apresentados na Tabela 1 e Figura 1.

Tabela 1: Tipos de ART

\begin{tabular}{|c|c|c|}
\hline Modelo & Definição & Exemplos \\
\hline $\begin{array}{l}\text { Monocable } \\
\text { Detachable } \\
\text { Gondola } \\
\text { (MDG) }\end{array}$ & $\begin{array}{l}\text { É o sistema ART mais comum, pois seu baixo custo é atrativo para implantação como } \\
\text { transporte público em países em desenvolvimento, tendo sido instalado em cidades na } \\
\text { Colômbia, Venezuela, Argélia, Cingapura e Brasil. Possui capacidade intermediária (compa- } \\
\text { tível com bondes urbanos). É propenso a paradas devido a ventos superiores a } 70 \mathrm{~km} / \mathrm{h} \text {. } \\
\text { Pode ser usado como linha principal de média capacidade ou alimentador para outras li- } \\
\text { nhas de trânsito de ordem superior (por exemplo, metrô e trem). }\end{array}$ & Figura 1 (a) \\
\hline $\begin{array}{l}\text { Bicable } \\
\text { Detachable } \\
\text { Gondola (BDG) }\end{array}$ & $\begin{array}{c}\text { Apresenta estabilidade para ventos superiores a } 70 \mathrm{~km} / \mathrm{h} \text { e pode chegar a velocidades } \\
\text { mais altas que o MDG. Utiliza a tecnologia dos bondes reversíveis, permitindo um maior } \\
\text { vão de cabo para superar condições de terrenos difíceis. Porém, seu benefício é mínimo } \\
\text { comparado ao custo de implantação e à complexidade do segundo cabo. Cada cabine } \\
\text { transporta no máximo } 17 \text { passageiros. }\end{array}$ & Figura 1 (b) \\
\hline $\begin{array}{l}\text { Tricable } \\
\text { Detachable } \\
\text { Gondola } \\
\text { (3S/TDG) }\end{array}$ & $\begin{array}{l}\text { Possui três cabos: dois são para apoio e o terceiro é para propulsão. Semelhante ao MDG e } \\
\text { BDG, suas cabines ficam em loop contínuo. Os cabos extras, ao contrário dos sistemas an- } \\
\text { teriormente apresentados, permitem o aumento da estabilização ao vento e capacidade } \\
\text { adicional (suportam mais peso). Podem transportar de } 6000 \text { a } 8000 \text { passageiros por ho- } \\
\text { ra/sentido graças as suas cabines largas, que comportam até } 35 \text { passageiros. }\end{array}$ & Figura 1 (c) \\
\hline Aerial Tram & $\begin{array}{l}\text { É o tipo original de teleférico, possuindo dois veículos, duas estações e pegas não destacá- } \\
\text { veis. São limitados em sua capacidade, mas com velocidade alta podem movimentar-se } \\
\text { bem entre dois pontos de distância curta (duas cabines não são eficientes para distâncias } \\
\text { longas). Os veículos estão ligados aos seus cabos de propulsão, com pegas não destacáveis } \\
\text { e duas cabines opostas às estações. Esses bondes aéreos também são conhecidos como } \\
\text { bondes reversíveis. Essa tecnologia originalmente foi desenvolvida para estações de esqui } \\
\text { e ao longo dos anos foi adotada como modo de transporte em outros lugares, como em } \\
\text { Portland - Nova York. }\end{array}$ & Figura $1(\mathrm{~d})$ \\
\hline
\end{tabular}

O uso da tecnologia CPT para o transporte público tem atraído o olhar dos governantes para um planejamento de transportes que visa a mobilidade urbana de quem reside em favelas. Porém, para que tal sistema seja abrangente, é necessário que haja um melhoramento urbano local com o intuito de tornar acessível seu entorno. Com isso, a seção 3 deste trabalho apresenta variáveis que podem ser utilizadas na análise da acessibilidade do espaço urbano em favelas. 

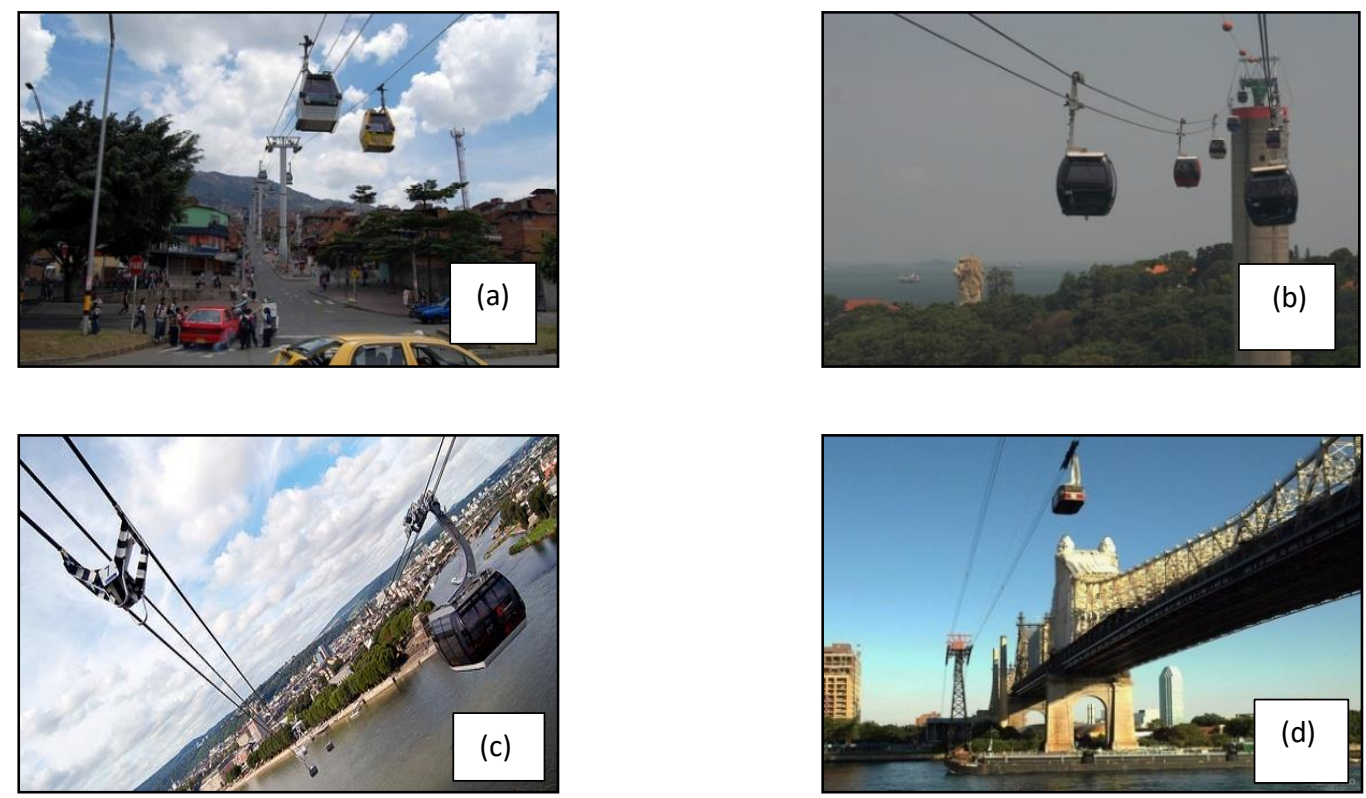

Figura 1. (a) Metrocable de Medellín (Colômbia), (b) Singapore Cable Car (Singapura), (c) Koblenz Rheinseilbahn (Alemanha) e (d) Roosevelt Island Tram (EUA). Fonte: Creative Urban Project, 2013

\section{MEDIDAS DE ACESSIBILIDADE DOS ESPAÇOS URBANOS EM FAVELAS}

0 espaço destinado à circulação de pedestres deve ser planejado, considerando seu entorno, para proporcionar ao pedestre um deslocamento com segurança e sem obstáculos (Monteiro, 2011). Entretanto, a realidade nem sempre é essa, sendo ainda pior nas vias internas das favelas.

O objetivo deste artigo é analisar a percepção da acessibilidade às estações do Teleférico do Alemão, segundo a percepção de passageiros do sistema. Neste caso, fatores como a distância percorrida para iniciar/finalizar a viagem pelo transporte e a comodidade, ou não, experimentada no percurso percebida pelas condições das calçadas, declividade do percurso, facilidade para cruzar as ruas no trajeto, existência de iluminação pública, segurança, podem interferir no acesso ao sistema de teleférico do Complexo do Alemão (Ferraz e Torres, 2004).

Para determinar quais variáveis são importantes na análise da acessibilidade dos espaços urbanos em favelas, realizou-se uma pesquisa bibliográfica em artigos acadêmicos e normas técnicas. Contudo, nesta pesquisa, não foram encontrados estudos focados exclusivamente na avaliação do espaço do pedestre em favelas, sendo necessária a adaptação para a análise destes espaços em comunidades carentes localizadas em regiões de aclive. Dentre os estudos levantados, foram selecionados aqueles cujas variáveis podem ser aplicadas neste tipo de avaliação, conforme apresenta a Tabela 2.

Tabela 2: Variáveis aplicáveis ao estudo de acessibilidade ao Teleférico do Alemão

(continua)

\begin{tabular}{ll}
\hline Variáveis & Referências \\
\hline Tipo de calçada & Mori e Tsukaguchi (1987) \\
Taxa de obstáculos & Mori e Tsukaguchi (1987) \\
Número de veículos estacionados & Mori e Tsukaguchi (1987) \\
Atratividade & Kisty (1994), Passmore (2007) e Fontenelle et al. (2008) \\
Conforto & Khisty (1994), Ferreira e Sanches (2001), Fontenelle et al. (2008), Larrañaga \\
& et al. 2011) e Figueirêdo e Maia (2013) \\
Segurança & Khisty (1994), Ferreira e Sanches (2001), Fontenelle et al. (2008), Antunes \\
& (2010) e Monteiro (2011) \\
Seguridade & Khisty (1994), Ferreira e Sanches (2001), Antunes (2010) e Monteiro (2011) \\
Conflitos & Sarkar (1995) \\
Obstruções nas calçadas & Sarkar (1995) \\
Possibilidades de quedas e ferimentos & Sarkar (1995) \\
\hline
\end{tabular}


Tabela 2: Variáveis aplicáveis ao estudo de acessibilidade ao Teleférico do Alemão

\begin{tabular}{ll}
\hline Variáveis & Referências \\
\hline Percepção de seguridade & Sarkar (1995) \\
Infraestrutura disponível para pedestres & Dixon (1996) \\
Conflitos entre pedestres e veículos motorizados & Dixon (1996) \\
Amenidades ao longo das vias & Dixon (1996) \\
Acessibilidade ao transporte coletivo & Dixon (1996) \\
Atratividade visual & Ferreira e Sanches (2001), Antunes (2010) e Larrañaga et al.(2011) \\
Qualidade da superfície & Gallin (2001) \\
Tipo de usuário & Gallin (2001) \\
Segurança pessoal & Gallin (2001) e Ackerson (2005) \\
Variáveis socioeconômicas & Rastogi e Krishna Rao (2001) \\
Informações sobre viagens realizadas & Rastogi e Krishna Rao (2001) \\
Piso & ABNT (2004) \\
Superfície de caminhada & Ackerson (2005) \\
Elementos da paisagem urbana & Ackerson (2005) \\
Iluminação & Passmore (2007) \\
Condições topográficas da rua, calçada e estradas & Passmore (2007) \\
\hline
\end{tabular}

\section{METODOLOGIA DE PESQUISA}

Com base nas medidas de acessibilidade dos espaços urbanos em favelas apresentadas na seção 3, foi desenvolvido um questionário estruturado, adotado como instrumento para realização da pesquisa. 0 modelo do questionário, aplicado em entrevistas pessoais, foi definido a partir de adaptações dos instrumentos citados na seção 3 para avaliação do espaço do pedestre e adaptações dos modelos utilizados por Ainsworth (2002), Ackerson (2005), Antunes (2010) e COPPETEC (2013). O questionário foi validado por cinco especialistas da área de transportes, acadêmicos do IME, da UFSCAR e da UFRJ, e com os passageiros do teleférico. Também foi realizado um teste piloto para detectar a necessidade ajustes no modelo.

O questionário, aplicado em cada uma das estações do Teleférico do Alemão, está dividido em quatro seções: características e perfil do entrevistado, caracterização da viagem e opinião do entrevistado, conforme apresentado no Anexo 1. Algumas questões do questionário tiveram o formato adaptado à escala Likert de cinco pontos (1932 apud Vieira; Dalmoro, 2008). Essas graduações estão presentes nas questões contidas nas seções caracterização da viagem e opinião do entrevistado: Aspectos que influenciaram o uso do teleférico, Aspectos que dificultariam o acesso ao teleférico e Aspectos importantes na escolha do trajeto.

0 tamanho da amostra para aplicação do questionário das entrevistas foi calculado com base na estimativa da proporção populacional. Adotou-se o grau de confiança de 95\%, com erro máximo de 10\%, para uma população de 70.000 habitantes do Complexo do Alemão (GERJ, 2010). Com isso, foi definido que o número de entrevistados deve ser superior a 96 indivíduos. Assim, foram realizadas 100 entrevistas em cinco estações que compõem o sistema do Teleférico do Alemão (Adeus, Baiana, Alemão, Itararé e Palmeiras). Excluiu-se a estação Bonsucesso por não estar situada dentro do Complexo do Alemão e ter seu atendimento mais amplo por atender também aos moradores do bairro de Bonsucesso. A amostra para cada estação foi de 20 entrevistados.

A aplicação do questionário foi realizada durante o ano de 2015 por entrevistas presenciais. As entrevistas ocorreram em dias variados, sempre entre terça a quinta-feira (dias úteis), no período de pico vespertino (entre 17 e $20 \mathrm{hrs}$ ). A escolha deste horário foi motivada por informações recolhidas na SuperVia, em entrevista com o gerente do teleférico, em que se comprovava o maior uso do sistema pelos moradores da comunidade neste período.

Os dados coletados foram tabulados, validados e tratados estatisticamente com o auxílio dos softwares Microsoft Excel 2010 e SPSS Statistics 22. Foram realizados testes t e ANOVA (Análise de variância), bem como a análise de clusters. 0 teste ANOVA permite a comparação entre médias de variáveis com 
duas ou mais categorias, tendo sido desenvolvido para verificar se há diferenças estatisticamente significativas entre as respostas de passageiros de diferentes estações. Optou-se por complementar a análise por meio do Teste Post Hoc (LSD) devido a sua maior precisão, uma vez que ele permite a identificação das categorias divergentes. Enfim, a análise de clusters agrupa os dados (neste caso, os passageiros) em classes que possuam semelhanças entre elas e os classifica. Dentro desta análise, o método mais utilizado é o $k$-means, que mede proximidade entre os grupos utilizando a distância euclidiana entre os centroides destes grupos. A seguir, apresenta-se a análise dos resultados.

\section{ANÁLISE DOS RESULTADOS}

Nesta seção, são apresentados os resultados da pesquisa survey. Inicialmente, é analisada a opinião dos passageiros do teleférico do Complexo do Alemão e, em seguida, apresenta-se a análise comparativa da percepção de passageiros de diferentes estações de embarque e desembarque.

\subsection{Pesquisa de opinião dos passageiros do teleférico do Alemão}

Entre o grupo de passageiros entrevistados, a maioria é do sexo feminino, tem entre 20 e 39 anos (50\%) e possui ensino fundamental incompleto (28\%) e ensino médio completo (28\%). As Tabelas 3 e 4 apresentam relações cruzadas entre o sexo do entrevistado e sua idade e o sexo do entrevistado e sua escolaridade.

Tabela 3: Relação entre sexo e faixa etária

\begin{tabular}{cccccccc}
\hline \multirow{2}{*}{ Sexo } & \multirow{2}{*}{$\%$} & \multicolumn{6}{c}{ Faixa etária (\%) } \\
\cline { 3 - 8 } & & $\mathbf{1 0 - 1 9}$ anos & $\mathbf{2 0 - 2 9}$ anos & $\mathbf{3 0 - 3 9}$ anos & $\mathbf{4 0 - 4 9}$ anos & $\mathbf{5 0 - 5 9}$ anos & $\mathbf{6 0}$ anos ou mais \\
\hline Feminino & 63 & 9 & 16 & 15 & 14 & 5 & 4 \\
Masculino & 37 & 7 & 9 & 10 & 5 & 6 & 0 \\
Total (\%): & 100 & 16 & 25 & 25 & 19 & 11 & 4 \\
\hline
\end{tabular}

Tabela 4: Relação entre sexo e escolaridade

\begin{tabular}{|c|c|c|c|c|c|c|c|c|c|c|}
\hline \multirow[b]{2}{*}{ Gênero } & \multirow[b]{2}{*}{$\%$} & \multicolumn{9}{|c|}{ Escolaridade (\%) } \\
\hline & & $\begin{array}{c}\text { Sem } \\
\text { instrução }\end{array}$ & $\begin{array}{l}\text { Ens. Fund. } \\
\text { Incomp. }\end{array}$ & $\begin{array}{l}\text { Ens. } \\
\text { Fund. } \\
\text { Comp. }\end{array}$ & $\begin{array}{l}\text { Ens. Médio } \\
\text { Incomp. }\end{array}$ & $\begin{array}{l}\text { Ens. } \\
\text { Médio } \\
\text { Comp. }\end{array}$ & $\begin{array}{l}\text { Ens. Sup. } \\
\text { Incomp. }\end{array}$ & $\begin{array}{l}\text { Ens. } \\
\text { Sup. } \\
\text { Comp. }\end{array}$ & $\begin{array}{c}\text { Pós } \\
\text { Incomp. }\end{array}$ & $\begin{array}{l}\text { Pós } \\
\text { Comp. }\end{array}$ \\
\hline Feminino & 63 & 2 & 19 & 5 & 12 & 19 & 4 & 0 & 1 & 1 \\
\hline Masculino & 37 & 2 & 9 & 4 & 9 & 9 & 3 & 0 & 0 & 1 \\
\hline Total (\%): & 100 & 4 & 28 & 9 & 21 & 28 & 7 & 0 & 1 & 2 \\
\hline
\end{tabular}

Observou-se que, em geral, os passageiros entrevistados não possuem veículos (carro, moto ou bicicleta) (78\%) e tampouco possui dificuldade de locomoção (98\%). Este resultado era esperado devido à dificuldade de acesso às gôndolas, uma vez que estas não param para embarque e desembarque. Foi identificado que $90 \%$ dos passageiros residem na comunidade e, dentre os que não residem no Complexo do Alemão, grande parte (80\%) reside em um bairro da zona norte carioca. Este resultado é reflexo dos horários e dias escolhidos para a realização das entrevistas, pois, segundo dados da SuperVia, aos finais de semana e nas férias, o número de visitantes, que vinham até de outros países, chegava a $60 \%$ do número de usuários totais do teleférico.

Os resultados indicam que este grupo utiliza o sistema de teleférico durante os dias úteis, variando entre diariamente (48\%) e 3 a 5 vezes por semana (22\%). A maioria dos entrevistados relatou como origem de sua viagem o trabalho (64\%) e como destino a própria residência (82\%). Esta característica pode ser explicada pelo fato da coleta de dados ter sido realizada no horário de pico vespertino, onde muitas pessoas estavam retornando de sua jornada de trabalho. Como local de origem da viagem, $69 \%$ dos usuários entrevistados relataram algum bairro da zona norte, sendo Bonsucesso o bairro mais citado. A estação do teleférico com mais embarques foi Bonsucesso (91\%) e desembarques foi Itararé 
(21\%), como apresentado pela Figura 2.0 horário das entrevistas influenciou este resultado, pois a maioria dos entrevistados estava retornando ao Complexo do Alemão, vindos de algum lugar fora da comunidade e acessava o teleférico pela estação Bonsucesso, "porta de entrada" da comunidade.

\section{Embarque/desembarque por estação}

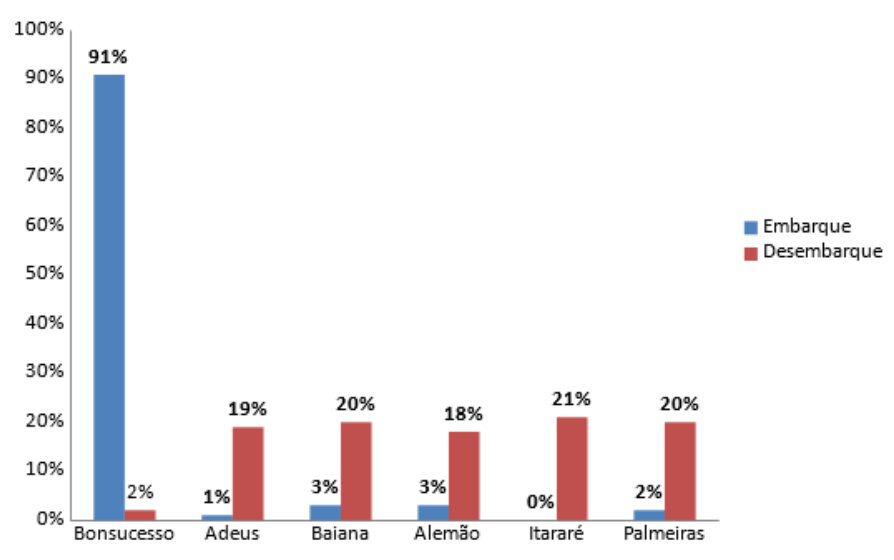

Figura 2. Percentual de embarques/desembarques por estação

Constatou-se que a maioria dos passageiros (81\%) caminha para ter acesso às estações do Teleférico do Alemão e levam em média 10 minutos para realizar esse trajeto (71\%), comprovando que eles residem próximo ao teleférico. Grande parte respondeu que, antes da instalação do teleférico, se deslocavam por caminhadas (58\%) e por Kombis (14\%), levando em média 26 minutos para realizar o percurso.

A Figura 3 apresenta a percepção dos entrevistados sobre os fatores influenciavam o uso do teleférico. A redução do tempo de viagem foi o fator que teve maior peso na escolha dos entrevistados em usar o transporte. É importante ressaltar que grande parte dos entrevistados não utiliza o transporte ferroviário em conjunto com o teleférico.

A maioria dos entrevistados residentes na comunidade considera que é fácil chegar ao Teleférico do Alemão (77\%), mesmo a região tendo o relevo bastante acidentado. Entretanto, consideram que o fator que mais dificulta o acesso às estações do teleférico é a sujeira (ou lixo) encontrada no trajeto que percorrem para chegar a uma estação, conforme apresentado na Figura 4. Além disto, o principal fator considerado na escolha da rota até uma estação do teleférico é distância percorrida, como apresentado na Figura 5.

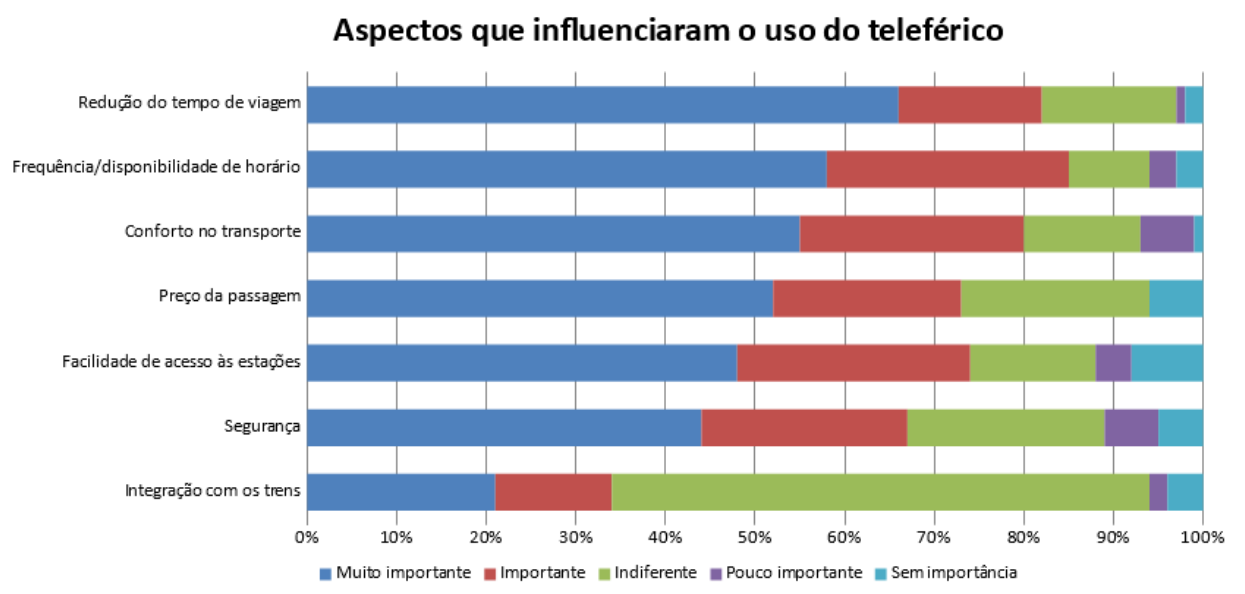

Figura 3. Importância dos aspectos que influenciam a escolha de utilizar o teleférico 


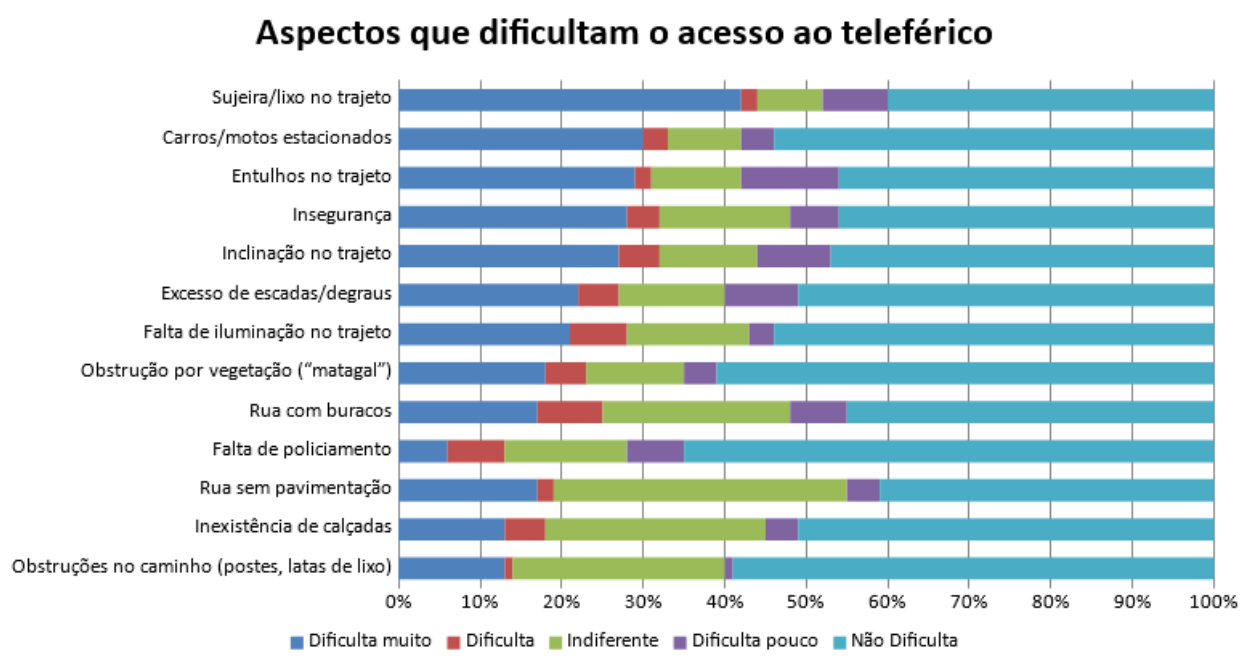

Figura 4. Nível de dificuldade de aspectos que atrapalhariam o trajeto até o teleférico

\section{Aspectos importantes para a escolha do trajeto}

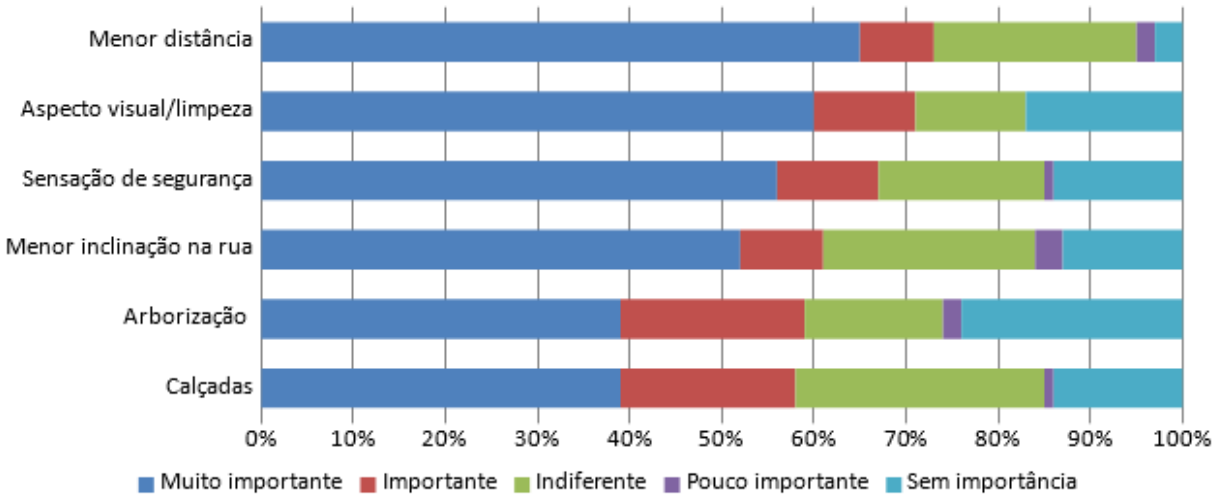

Figura 5. Importância de aspectos que influenciam na escolha de caminho às estações

Enfim, 69\% dos entrevistados estão satisfeitos com o atual horário de funcionamento do teleférico. Para $60 \%$ dos usuários, o serviço do teleférico foi classificado como ótimo.

\subsection{Análise dos resultados de acordo com as estações de embarque e desembarque}

Durante as entrevistas, foi apresentado a cada entrevistado um mapa com o entorno das estações, dividido em quadrículas, para que o mesmo indicasse o local aproximado da origem/destino de sua viagem, mantendo a privacidade do lugar de moradia do entrevistado e permitindo traçar a área de influência de cada estação, que pode ser definida como uma delimitação para o alcance do atendimento da maior parte de sua demanda. Assim, os raios de influência das estações foram obtidos, tendo a distância euclidiana como base de cálculo, com o auxílio do software TransCAD (Tabela 5).

A representação gráfica das áreas de influência, apresentada na Figura 6, destaca que as estações Itararé e Palmeiras possuem os maiores raios. Observou-se, nos locais, que o entorno destas estações e da estação Alemão é menos íngreme que as demais. 0 menor raio é observado na estação Adeus, que destaca o quão difícil é acessá-la devido ao relevo bastante acidentado, principalmente pelos moradores da parte baixa do morro, pois necessitam percorrer uma longa escadaria em más condições de uso. 
Tabela 5: Raio de influência de cada estação

\begin{tabular}{cc}
\hline Estação & Raio $\mathbf{( k m )}$ \\
\hline Adeus & 0,20 \\
Baiana & 0,21 \\
Alemão & 0,24 \\
Itararé & 0,37 \\
Palmeiras & 0,30 \\
\hline
\end{tabular}

Observa-se que a área de influência da estação Palmeiras tangencia as ruas Canitar e Joaquim de Queiroz, que são vias locais asfaltadas, com calçamento e pontos de comércio, onde são oferecidos os serviços de Kombi (cabritinho) e mototáxi. As áreas de influência das estações Itararé e Alemão tangenciam a Rua Joaquim de Queiroz e se aproximam da Estrada do Itararé, por onde circulam linhas de ônibus convencionais. A área de influência da estação Baiana tangencia apenas a Estrada do Itararé. Estas vias acabam se tornando "limitadores" da área de influência, pois, para os moradores que estão no sopé do morro e próximos a estas vias, os ônibus ou o serviço de Kombi se tornam mais eficientes e econômicos.

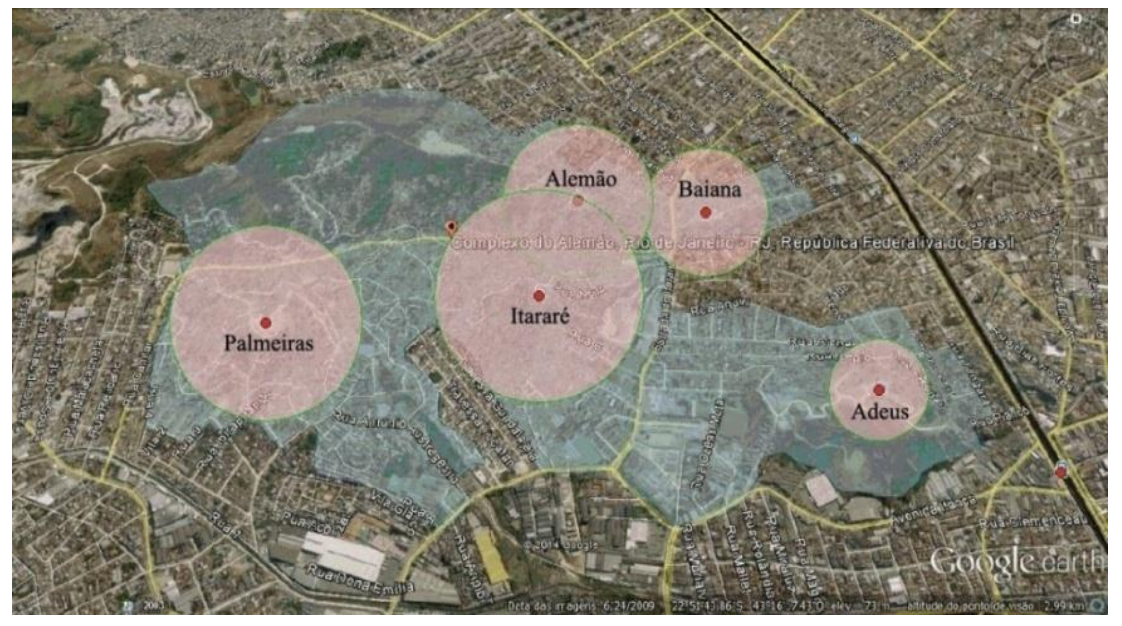

Figura 6. Representação gráfica das áreas de influência das estações

Independente da estação de embarque/desembarque, o deslocamento pendular foi o motivo de viagem mais relatado pelos entrevistados (70\% Adeus, 70\% Baiana, 75\% Alemão, 60\% Itararé e 65\% Palmeiras). A maioria dos respondentes que embarcam/desembarcam nas estações (50 a 100\%) se deslocam a pé até elas, demorando, em média, 10 minutos para realizar este percurso. A falta de integração com outros modos de transporte torna-se um fator importante para explicar a baixa demanda no uso do teleférico.

Independente da estação de embarque/desembarque, o deslocamento pendular foi o motivo de viagem mais relatado pelos entrevistados (70\% Adeus, 70\% Baiana, 75\% Alemão, 60\% Itararé e 65\% Palmeiras). A maioria dos respondentes que embarcam/desembarcam nas estações (50 a 100\%) se deslocam a pé até elas, demorando, em média, 10 minutos para realizar este percurso. A falta de integração com outros modos de transporte torna-se um fator importante para explicar a baixa demanda no uso do teleférico.

Não houve diferenças significativas na percepção dos usuários de diferentes estações sobre a qualidade do serviço prestado. A Tabela 6 apresenta as variáveis com diferenças significativas para as estações do teleférico, de acordo com os resultados do teste ANOVA, para os "Aspectos que influenciam o uso do teleférico", "Facilidade de acesso às estações", "Aspectos que dificultam o acesso às estações" e "Aspectos importantes para a escolha do trajeto à estação". Para complementar a análise do teste ANOVA, foi realizado o teste Post Hoc (LSD) devido a ter maior precisão para identificar as categorias divergentes. 
Tabela 6: Variáveis utilizadas no teste ANOVA

\begin{tabular}{|c|c|}
\hline \multicolumn{2}{|c|}{ Aspectos que influenciam o uso do teleférico } \\
\hline Variáveis & Sig \\
\hline Preço da passagem & 0,048 \\
\hline Redução do tempo de viagem & 0,028 \\
\hline Conforto no transporte & 0,030 \\
\hline \multicolumn{2}{|c|}{ Facilidade de acesso a estação } \\
\hline Classificação da chegada ao teleférico & 0,002 \\
\hline \multicolumn{2}{|c|}{ Aspectos que dificultam o acesso às estações } \\
\hline Inexistência de calçadas & 0,000 \\
\hline Rua sem pavimentação & 0,000 \\
\hline Rua com buracos & 0,008 \\
\hline Falta de iluminação no trajeto & 0,015 \\
\hline Obstrução por vegetação (“matagal”) & 0,000 \\
\hline \multicolumn{2}{|c|}{ Aspectos importantes para a escolha do trajeto à estação } \\
\hline Aspecto visual/limpeza & 0,001 \\
\hline Arborização & 0,028 \\
\hline Menor inclinação na rua & 0,007 \\
\hline Calçadas & 0,018 \\
\hline Menor distância & 0,050 \\
\hline Sensação de segurança & 0,023 \\
\hline
\end{tabular}

De acordo com os resultados do teste Post Hoc, a percepção dos passageiros da estação Palmeiras quanto aos aspectos que influenciam o uso do teleférico apresentou diferenças significativas para a variável "preço da passagem". Os entrevistados desta estação atribuíram menor importância a este aspecto na sua escolha em utilizar o serviço do teleférico. Acredita-se que esta diferença se deva ao fato de que a maioria dos entrevistados da estação Palmeiras não seja morador local e, por isto, não estão cadastrados para o uso de passagens gratuitas. A percepção do mesmo grupo de passageiros também apresentou diferenças significativas para a variável "redução do tempo de viagem", pois atribuíram menor importância para a influência deste aspecto na utilização do transporte. Supõe-se que esta diferença se deva ao fato de que, por estarem próximos às ruas Canitar e Joaquim de Queiroz, estes entrevistados possuam outras opções de transportes oferecidas pelas Kombis e mototáxis, de modo que o serviço do teleférico trouxe um menor impacto na redução do tempo de viagem destes respondentes. 0 conforto das gôndolas também não pareceu atrair os entrevistados da estação Palmeiras, pois atribuíram baixo grau de importância para este aspecto.

Os passageiros da estação Palmeiras também atribuíram menor importância para a facilidade de acesso às estações que os demais usuários. Tal fato pode ser explicado pela menor inclinação da área no entorno da estação Palmeiras, bem como pela oferta de outros modais em ruas próximas a estação. Além disto, os entrevistados da estação Palmeiras são, em sua maioria, visitantes e não percorreram o interior da favela para chegar ao teleférico, não sofrendo as dificuldades impostas pelo relevo acidentado do Complexo do Alemão.

Segundo resultados referentes aos aspectos que dificultariam o acesso às estações, o teste Post Hoc mostrou que os entrevistados das estações Alemão e Palmeiras são indiferentes em relação à influência das variáveis "inexistência de calçadas", "ruas sem pavimentação" e "ruas com buracos" no grau de dificuldade de acesso às estações. Entretanto, os usuários das estações Adeus, Baiana e Itararé consideraram que estas variáveis são de baixa dificuldade no acesso às estações. Os respondentes da estação Palmeiras mostraram maior insatisfação em relação à iluminação pública no trajeto às estações, o que indica a necessidade da uma interferência da Prefeitura neste quesito no entorno da estação. Para os entrevistados das demais estações, esta variável apresentou pouca influência no grau de dificuldade de acesso às estações, indicando que a iluminação pública está em boas condições no entorno destas estações. De acordo com os respondentes das estações Baiana e Itararé, a vegetação não obstrui o caminho percorrido por eles para acessar as estações. Já os entrevistados da estação Palmeiras declararam que a 
obstrução de vias por vegetação dificulta um pouco o acesso às estações, enquanto os passageiros das estações Adeus e Alemão são indiferentes a este aspecto.

Em relação à análise dos "Aspectos importantes para a escolha do trajeto à estação", os itens "limpeza das vias" e "presença de arborização" receberam as piores avaliações dos entrevistados das estações Itararé e Palmeiras, que atribuíram menor importância destes fatores na escolha de trajeto comparado às respostas dadas pelos grupos das estações Adeus, Baiana e Alemão. É importante destacar que alguns entrevistados, residentes do entorno da estação Palmeiras, avaliaram de maneira negativa o item "arborização" por medo de que as árvores sirvam de esconderijo para quem deseja cometer atos de violência. Este resultado é contrário ao que era esperado, pois, de acordo com os conceitos básicos de acessibilidade, a arborização traz mais conforto aos pedestres, tendo assim um impacto positivo na escolha da rota.

Uma rua menos inclinada é um fator que aumenta muito a probabilidade de escolha de uma rota como local de caminhada, de acordo com os entrevistados das estações Adeus e Baiana, tendo este aspecto importância menor para os passageiros das estações Alemão, Itararé e Palmeiras. Isto pode ser explicado pelo fato de que o entorno destas estações ser mais plano do que das estações Adeus e Baiana. Possuir calçadas é um fator importante para a escolha de um caminho até a estação de acordo com os entrevistados das estações Adeus, Baiana e Alemão. Já o trajeto mais curto teve maior peso na avaliação dos respondentes da estação Baiana, apesar de ter sido o critério melhor avaliado por todos os entrevistados. Sentir-se seguro nas vias de acesso ao teleférico obteve melhor avaliação para os passageiros das estações Adeus, Baiana e Alemão que atribuíram uma maior importância deste fator para a escolha do trajeto.

Assim, percebe-se que os entrevistados das estações Adeus e Baiana atribuíram maiores graus de importância a todos os aspectos que influenciam na escolha do trajeto às estações. A percepção destes grupos se diferenciou da avaliação dos passageiros da estação Alemão apenas no fator "inclinação", uma vez que o entorno da estação apresenta relevo mais plano em relação às demais. Destaca-se que a semelhança na avaliação entre os entrevistados das estações Baiana e Alemão já era esperada devido à proximidade das duas estações.

Tabela 7: Crosstab entre grupo e estações (Análise de cluster)

\begin{tabular}{ccccccc}
\hline \multirow{2}{*}{ Grupo } & \multicolumn{7}{c}{ Estações } & \multirow{2}{*}{ Total grupo } \\
\cline { 2 - 6 } & Adeus & Baiana & Alemão & Itararé & Palmeiras & \\
\hline 1 & 3 & 1 & 9 & 1 & 7 & 21 \\
2 & 6 & 2 & 2 & 1 & 7 & 18 \\
3 & 6 & 9 & 6 & 11 & 3 & 35 \\
4 & 5 & 8 & 3 & 7 & 2 & 25 \\
5 & 0 & 0 & 0 & 0 & 1 & 1 \\
\hline
\end{tabular}

Para complementar este estudo por estações, foi realizado uma análise de clusters, que tem como objetivo agrupar determinados dados (no caso, os passageiros) em classes que são semelhantes entre si, classificando-os. Com isso, esperava-se verificar se os respondentes das mesmas estações seriam agrupados de acordo com a sua estação de embarque/desembarque. Neste estudo, foi adotado o método $k$-means para encontrar uma parcela de dados que "minimize o quadrado da distância euclidiana ao centro do cluster, procurando grupos homogêneos" (Sousa et al, 2003). Entretanto, ao se realizar a análise de cluster, dividindo os respondentes, passageiros do Teleférico do Alemão, em cinco grupos, não se obteve uma concentração maior de passageiros de determinadas estações de embarque/desembarque em um mesmo grupo, conforme observado na Tabela 7.

\section{CONCLUSÕES}

0 artigo apresentou uma análise da acessibilidade às estações de Teleférico do Alemão, com base na 
percepção dos passageiros, com o objetivo de analisar se as características do entorno influenciam ou não a decisão de usar o teleférico.

0 resultado da pesquisa apontou que fatores como a redução do tempo de viagem, a boa disponibilidade de horário, o conforto da viagem e o preço da passagem foram determinantes para a utilização do teleférico, de acordo com a maioria dos entrevistados. 0 mesmo grupo também deu importância a itens como a presença de sujeira/lixo no trajeto percorrido, carros/motos estacionados irregularmente e entulhos descartados na via como itens que dificultam o acesso às estações do teleférico.

Outros fatores como insegurança, inclinação acentuada do trajeto e o excesso de degraus/escada no caminho, além de dificultarem o acesso ao teleférico, impactam no interesse dos entrevistados em escolher o teleférico para fazer seus deslocamentos. Vale ressaltar que a localização das estações no topo dos morros também é um empecilho para quem as acessa, pois a região não teve um tratamento urbanístico adequado e não há integração com os transportes existentes no interior da favela (Kombis e mototáxis).

Mesmo com empecilhos que tendem a desestimular a utilização do teleférico, a análise permitiu identificar que grande parte dos entrevistados tende a escolher o trajeto mais curto para chegar ao teleférico, este sendo limpo, seguro e com menor inclinação possível para facilitar sua caminhada.

Enfim, para o enriquecimento e aprimoramento deste trabalho no futuro, recomenda-se que seja realizada a análise das vias de acesso para cada estação do teleférico, com proposição de indicadores para analisar a acessibilidade local pelo pedestre, obtidos através de mapeamento local com o desenvolvimento de ficha de avaliação do espaço e levantamento fotográfico para auxiliar no processo. Desta forma, seria possível modelar a acessibilidade às estações em função das características pesquisadas (características do indivíduo, do entorno, do trajeto etc). Contudo, com o fechamento do Teleférico do Alemão por tempo indeterminado, não há certeza se haverá possibilidade de um novo estudo para aprimorar este trabalho futuramente.

\section{REFERÊNCIAS}

Associação Brasileira de Normas Técnicas (2004). NBR 9050 - Acessibilidade à edificações, mobiliário, espaços e equipamentos urbanos . 2. ed. Rio de Janeiro: ABNT. 97 p.

Ackerson, K. J. (2005). A GIS approach to evaluating streetscape and neighborhood walkability. 103 p. Dissertação (Mestrado em Planejamento urbano e regional) - Universidade de Oregon. Oregon. Disponível em: < https://scholarsbank.uoregon.edu/xmlui/handle/1794/1286>. Acesso em: 30 jul. 2014.

Agrawal, A. W. et al. (2008). How far, by which route and why? A spatial analysis of pedestrian preference. Journal of Urban Design, United Kingdon, v. 13, n. 1, p. 81-98. DOI: 10.1080/13574800701804074

Ainsworth, B. E. (2002). Environmental supports for physical activity questionnaire. Universidade da Carolina do Sul. Disponível em: < http://activelivingresearch.org/environmental-supports-physical-activity-questionnaire>. Acesso em: 15 jul. 2014.

Alshalalfah, B. et al. (2010). Aerial ropeway transit: exploring its potential for makkah. Toronto: Universidade de Toronto. Disponível em: < http://civil.engineering.utoronto.ca/wp-content/uploads/2015/08/Makkah-Project-Report-Part-1.pdf>. Acesso em 10 jul. 2014.

Antunes, J. C. (2010). Acessibilidade aos pontos de ônibus: estudo de caso em São Carlos. 223 p. Dissertação (Mestrado em Engenharia Urbana) - Universidade Federal de São Carlos. São Carlos, SP.

COPPETEC (2013). Teleférico do Alemão: marco regulatório. Rio de Janeiro, RJ. 2013. 58p.

Dale, Steven (2013). Cable car confidential.: the essential guide to cable cars, urban gondolas \& cable propelled transit 1. ed. Toronto: Creative Urban Project.

Dixon, L. B. (1996). Bicycle and pedestrian level-of-service performance measures and standards for congestion management systems. Transportation Research Record, Estados Unidos, v. 1538, p. 1-9. DOI: 10.3141/1538-01.

Ferraz, A. C. P.; Torres, I. G. E. (2004). Transporte público urbano. São Carlos, SP: RiMa. 410 p.

Ferreira, M. A. G.; Sanches, S. P. (2001). Índice de qualidade das calçadas - IQC. Revista dos Transportes Públicos, n. 91, p. 47-60. Disponível em: <http://files.antp.org.br/2016/4/5/revista-completa-91.pdf>.

Figueirêdo, C. F.; Maia, M. L. A. (2013). 0 pedestre e o ambiente de circulação: condições e avaliação dos deslocamentos a pé nas cidades. In: CONGRESSO BRASILEIRO DE TRANSPORTE E TRÂNSITO, 19., 2013. Anais... Brasília: ANTP. Disponível em: <http:/files-erver.antp.org.br/5dotSystem/download/dcmDocument/2013/10/06/4D359BE4-AAD1-41F6-953C54F7C9B9CCBF.pdf>.

Fontenelle et al. (2008). Avaliação da qualidade das calçadas relacionada com o fluxo de pedestres no centro de Florianópolis. Disponível em: < http://www.usp.br/nutau/CD/163\%20199.pdf >. Acesso em: 23 jul. 2014. 
Gallin, N. (2001). Quantifying pedestrian friendliness: guidelines for assessing pedestrian level of service. Road and Transport Research, v. 10, n. 1, p. 47-55. Disponível em: <https://trid.trb.org/View/732751>

GERJ (2010). Censo favelas. Rio de Janeiro, RJ: Secretaria de Estado da Casa Civil. Disponível em: <http://www.egprio.rj.gov.br/Conteudo.asp?ident=285>. Acesso em: 09 out 2014.

Gonçalves, C. M. (2015). Transporte público em favelas: análise das características dos usuários e acessibilidade do Teleférico do Alemão. 154p. Dissertação (Mestrado em Engenharia de Transportes) - Instituto Militar de Engenharia.

Gonçalves, J. A. M. et al. (2012). Investimentos no sistema ferroviário da região metropolitana Rio de Janeiro: Inclusão social e captação de usuários nas comunidades carentes. In: CONGRESSO DE ENSINO E PESQUISA EM TRANSPORTE, $24 ., 2012$. Anais... Joinville: ANPET. Disponível em: <http://redpgv.coppe.ufrj.br/index.php/pt-BR/producao-da-rede/artigos-cientificos/2012-1/686-inclusao-social-sistema-metroferroviario-anpet-2012/file>

ITRANS (2004). Relatório final: mobilidade e pobreza. Brasília, DF. 42 p.

Khisty, C. J. (1994). Evaluation of pedestrian facilities: beyond the level-of-service concept. Transportation Research Board, $\mathrm{n}$. 1438, p. 45-50. Disponível em: <http://onlinepubs.trb.org/Onlinepubs/trr/1994/1438/1438-006.pdf>. Acesso em : 25 jul. 2014.

Larrañaga, A. M.; Ferret, G.; Cybis, H. B. B. (2011). Avaliação da qualidade das calçadas: efeito do tamanho da amostra e do plano amostral. In: CONGRESSO DE ENSINO E PESQUISA EM TRANSPORTE, 25., 2011. Anais.... Belo Horizonte: ANPET. Disponível em: <http://redpgv.coppe.ufrj.br/index.php/pt-BR/producao-da-rede/artigos-cientificos/2011-1/554-avaliacao-da-qualidade-das-calcadas-efeito-do-tamanho-da-amostra-e-do-plano-amostral/file>.

Lindau, L. A. et al. (2011). Desafios para o transporte sustentável em assentamentos precários. In: CONGRESSO DE ENSINO E PESQUISA EM TRANSPORTE, 25., 2011. Anais.... Belo Horizonte: ANPET. Disponível em:

<http://redpgv.coppe.ufrj.br/index.php/es/produccion/articulos-cientificos/2011-1/534-desafios-para-o-transporte-ustentavel-em-assentamentos-urbanos-informais-precarios/file>.

Lima, R. S. (1998). Expansão urbana e acessibilidade : o caso das cidades médias brasileiras. 91 p. Dissertação (Mestrado em Transportes) - Universidade de São Paulo. São Paulo, SP.

Meirelles, S. L. G. et al. (2012). Teleférico: uma solução para a questão da dificuldade de mobilidade no Complexo do Alemão/RJ. Revista Polêmica, v. 11, n. 4, p. 612-619. Disponível em:

<http://www.e-publicacoes.uerj.br/index.php/polemica/article/view/4328>

Monteiro, F. B. (2011). Avaliação de espaços urbanos para pedestres e ciclistas visando a integração com o transporte de massa. 236p. Dissertação (Mestrado em Engenharia de Transporte) - Instituto Militar de Engenharia.

Mori, M.; Tsukaguchi, H. (1987). A new method for evaluation of level of service in pedestrian facilities. Transportation Research Part A: General, v. 21, n. 3, p. 223-234. DOI: 10.1016/0191-2607(87)900161>

Passmore, D. (2007). The missing leg: the experience of walking public transit in São Paulo, Brazil. Disponível em: <http://dylanpassmore.com/Passmore\%20(2007)\%20The\%20Missing\%20Leg\%20 \%20small.pdf>. Acesso em: 16 jun. 2014.

Raia Junior, A.A; Silva, A. N. R.; Brondino, N. C. M. (1997). Comparação entre medidas de acessibilidade para aplicação em cidades brasileiras de médio porte. In: CONGRESSO DE ENSINO E PESQUISA EM TRANSPORTE, 11., 1997. Anais... Rio de Janeiro, ANPET.

Rastogi, R; Krishna Rao, K. V. (2002). Survey design for studying transit access behaviour in Mumbai city, India. Journal of Transportation Engineering, v. 128, n. 1, p. 68-79. DOI: 10.1061/(ASCE)0733-947X(2002)128:1(68)>

Sarkar, S. (1995). Evaluation of safety for pedestrian at macro and micro levels in urban areas. Transportation Research Record, n. 1502, p. 105-118. Disponível em: <https://trid.trb.org/view.aspx?id=453076>

Silva, V. R. A. (2012). Contexto y impacto potencial del teleférico sobre la población de Complexo de Alemão, Rio de Janeiro. In: Dávila, Julio D. (org.). Movilidad urbana \& pobreza: aprendizajes de Medellín y Soacha, Colombia. p. 186-193.

Sousa, L. et al. (2003). Qualidade de vida e bem-estar dos idosos: um estudo exploratório na população portuguesa. Revista Saúde Pública, n. 37, p. 364-371. DOI: 10.1590/S0034-89102003000300016>

Vieira, K. M., Dalmoro, M. (2008). Dilemas na construção de escalas tipo Likert: o número de itens e a disposição influenciam nos resultados? In: ENCONTRO DA ANPAD, 33., 2008. Anais... Rio de Janeiro. Disponível em:

<http://www.anpad.org.br/admin/pdf/EPQ-A1615.pdf> 


\section{ANEXO}

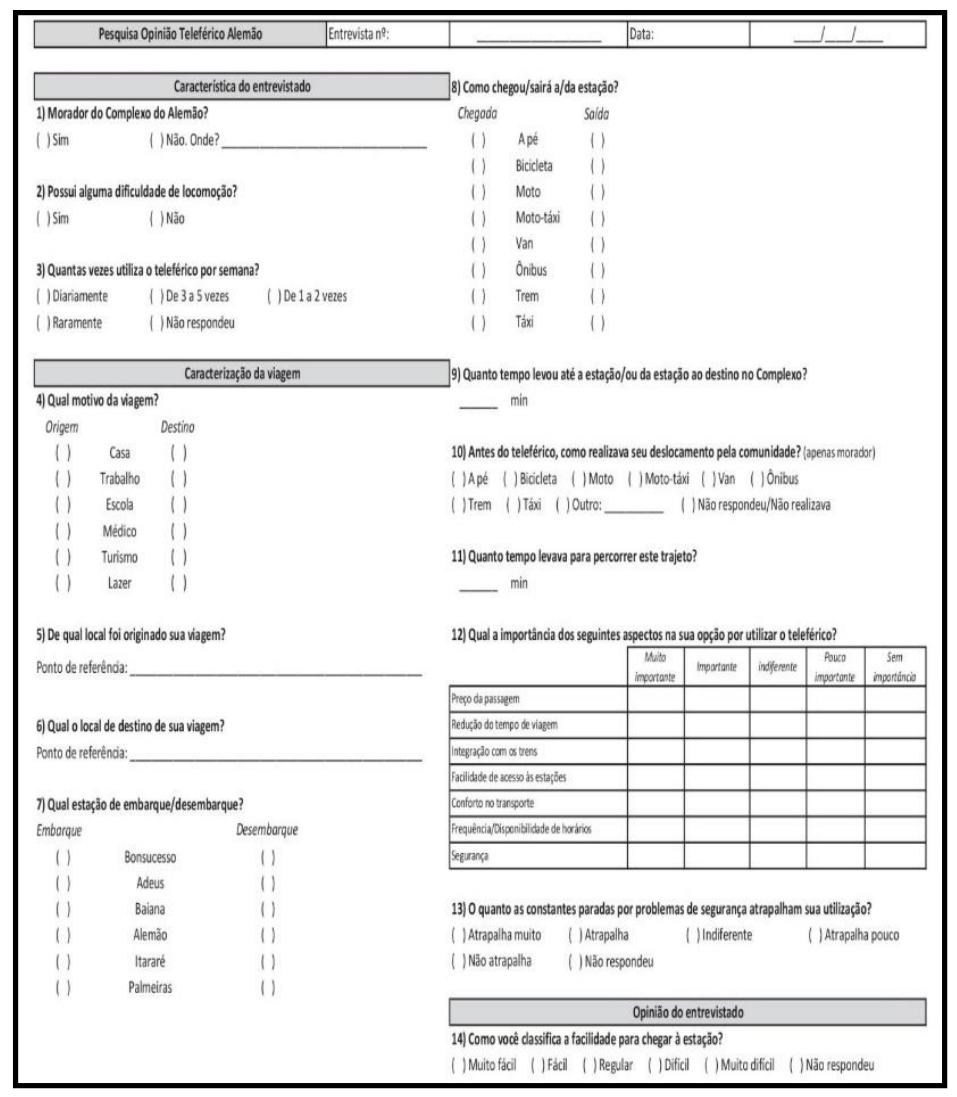

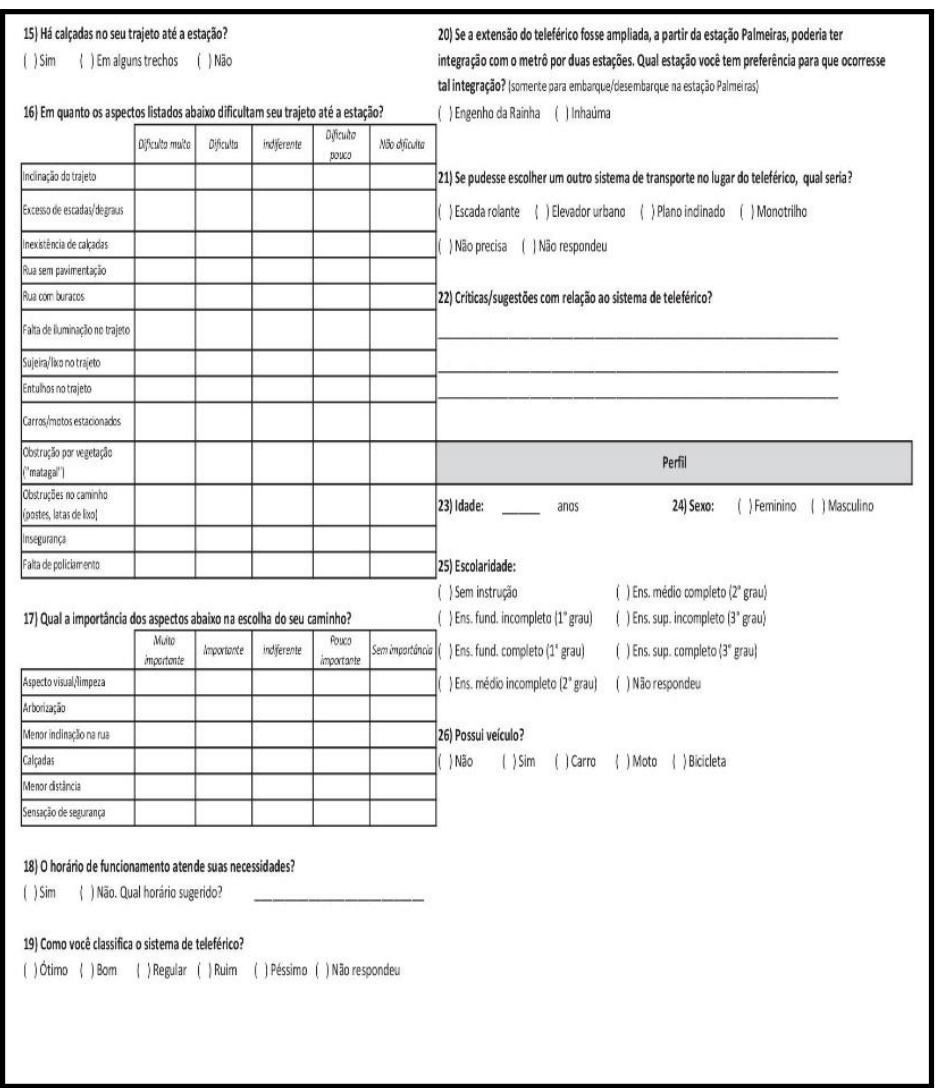

